\title{
Results in the Treatment with Twin Block Polymeric Appliance of the Retrognathic Mandible in Sleep Apnea Patients
}

\author{
OVIDIU DANUT RADESCUㄴ, SILVIU ALBU ${ }^{2}$, MIHAELA BACIUT ${ }^{3}$, SIMION BRAN ${ }^{3}$, ANDREEA CODRUTA COMAN ${ }^{4}$, \\ EDWIN SEVER BECHIR ${ }^{5}$, MARIANA PACURAR ${ }^{5 *}$, DOINA ADINA TODEA \\ ${ }^{1}$ Iuliu Hatieganu University of Medicine and Pharmacy, Department of Orthodontics and Dentofacial Orthopedics, 8 Victor Babes \\ Str., 400012 Cluj Napoca, Romania \\ ${ }^{2}$ Iuliu Hatieganu University of Medicine and Pharmacy, Department of ENT, 8 Victor Babes Str., 400012, Cluj Napoca, Romania \\ ${ }^{3}$ Iuliu Hatieganu University of Medicine and Pharmacy, Department of Maxillofacial Surgery and Implantology, 8 Victor Babes Str., \\ 400012, Cluj Napoca, Romania \\ ${ }^{4}$ Iuliu Hatieganu University of Medicine and Pharmacy, Department of Pneumology, 8 Victor Babes Str., 400012, Cluj Napoca, \\ Romania \\ ${ }^{5}$ University of Medicine and Pharmacy, Department of Orthodontics and Dentofacial Orthopedics, 38 Gh. Marinescu Str., 540139 \\ Tirgu Mures, Romania
}

\begin{abstract}
Obstructive sleep apnea syndrome (OSAS) in children is characterized by recurrent events of partial or complete upper airway obstruction during sleep. Functional orthopedics has been used for patients who have OSAS and craniofacial anomalies because they change the mandible posture forwards, improving the respiratory function. In present, much attention is accorded to the relationship between respiratory function and facial morphology. This study combines the cephalometric measurements and cardio-respiratory polygraphy, in order to analyze the effects of a modified functional Twin Block polymeric appliance on respiratory variables in OSAS patients. The chief complaints of the included in study patients was the crooked teeth and the teasing about their smile. Pretreatment facial photographs show labial position of anterior teeth, gummy smile, a large overjet, incompetent lips and retrognathic mandible. The patients underwent overnight cardio-respiratory polygraphic tests in the same Sleep Laboratory, before and after mandibular advancement device treatment. At the end of the orthopedic treatment phase, the beneficial result of this study was the mandible correction, the maxilla restrained, over jet decreased, improving the facial profile and reintegration of the patient in the school social environment. The education of the parents and of the small patients to recognize the symptoms of sleep apnea and to apply the available effective treatments with a positive social impact on self-esteem and which recovers the facial aesthetics and functionality is a stringent necessity.
\end{abstract}

Keywords: OSAS, Functional appliance, Mandibular advancement, Cardio-Respiratory Polygraphy, Cephalometrics measurments

Obstructive sleep apnea syndrome in children is characterized by recurrent events of partial or complete upper airway obstruction during sleep, resulting in disruption of normal gas exchange (intermittent hypoxia and hypercapnia) and sleep fragmentation [1].

The obstructive apnea hypopnea index was defined as the number of obstructive apneas and hypopnea (AHI) per hour of total sleep apnea time. Symptoms were identified as defined by the American Sleep Disorders Association Task Force report [2-3].

Dentofacial orthopedics have been used for patients who have OSAS and craniofacial anomalies, because they change the mandible posture and potentially enlarge the upper airway, improving the respiratory function by increasing the upper airspace [4] .

Increased risk for pediatric OSAS occur in children with allergy, a family history of OSAS, children born prematurely and in children with chronic upper and lower respiratory tract disease [5-9].

Much attention has been paid to the relationship between respiratory function and facial morphology in orthodontics [10].

The most common cause of OSAS due to airway obstruction is hypertrophy of the tonsils and adenoids [11]. Patients may complain of tiredness or fatigue, behavioral abnormalities [12], hyperactivity, poor hearing, non-obese patients often have often mandibular retrognathia [13], a high-arched narrow palate [14], macroglossia, enlarged tonsils [15], temporomandibular joint abnormalities [16]. Treatment of sleep disorders includes both dental and medical benefits [17].

Dental resins are commonly used in dentistry for different purposes, including anti-snoring or bruxism dental appliances, due to their advantages as good physical properties, sufficient strength, low water sorption, low solubility [18]. A large number of studies were published regarding the materials for different dental appliances, but it has not been possible to reach a consensus about the product that represents the gold standards [19].

The aim of this study was to determine and to measure the specific parameters, by cardio-respiratory polygraphs and by orthopedic/orthodontic measurements, for youth patients with dentoalveolar disharmony, retrognathic mandible and sleep apnea syndrome and with an allergic background in social school environment after the use of polymeric mandibular advancement device.

\section{Experimental part}

\section{Materials and methods}

The achievements of modified polymeric functional Twin Block appliance require the covering of some clinical and technical steps. After medical approval of the

\footnotetext{
*email: marianapac@yahoo.com; Phone: 0040744952183
} 
procedure, the orthodontist realized the alginate impressions of the upper and lower dental arch and the dental technician manufactured the customized protruding dental device. Inter-occlusal wax bite registration was performed to obtain maximal mandibular advancement. The construction bite was recorded with a vertical opening of 2-3 $\mathrm{mm}$ between upper and lower incisor and with sagittal advancing of the mandible at an edge to edge incisor relationship. The two protruding dental devices were manufactured from heat-cured acrylic resin and included the dental arches with tooth coverage, excepting the frontal area in both arches. Two expansion screws and Adams clasps (for optimizing the retention) were used at the first molars level. The devices were activated by means of slow expansion protocol of one turn every week $0.25 \mathrm{~mm}$ for transverse modification. For the correction of frontal teeth position in sagittal plane and to improve upper and lower incisor angle with the skeletal base, were used springs, an anterior bow for the upper incisors and a palatal mushroom loop. The upper and lower bite blocks interlock at a $70^{\circ}$ angle when engaged in full closure. The inclined planes of the Twin-block appliance are shown to be effective in maintaining forward mandibular posture even when the patient is asleep. The devices were fitted and adjusted until the patient feels comfortable. These devices permits movement of the jaws allowing forward reposition of the mandible, pharyngeal space becomes larger and opens upper airway space. The patients have been using these functional oral appliances for one year. The estimated average treatmenttime is 12 months this includes an active phase of 6 to 9 months; they achieve functional correction of malocclusion by transmitting favorable occlusal forces to occlusal inclined planes covering the posterior teeth.

At beginning and at the end of orthodontic treatment, lateral cephalometric radiographs and sleep polygraphs tests were conducted and than, these test were compared. The sleep diagnostic equipment was represented by Stardust Sleep Recorder, manufactured by Philips Respironics. The cephalometric point's analyses were based on Tweed and Steiner methods. All of the cephalometric analyses were performed by the same orthodontist (ODR). The used imaging system was represented PaX-Reve 3D type by Vatech production.

We exemplifying with a young 8 year old female patient with crooked teeth, nevertheless because her colleagues were teasing about her smile and made fun of her face look. The young patient was known with allergic history as she used Nasonex at the age of 3 and had the recommendation for antihistamine medication. Pretreatment facial photographs showed labial flare of the front teeth, gummy smile, a large overjet, incompetent lips and retrognathic mandible, transverse dentoalveolar discrepancy - An Angle Class II/1 molar relationship and mouth breather.
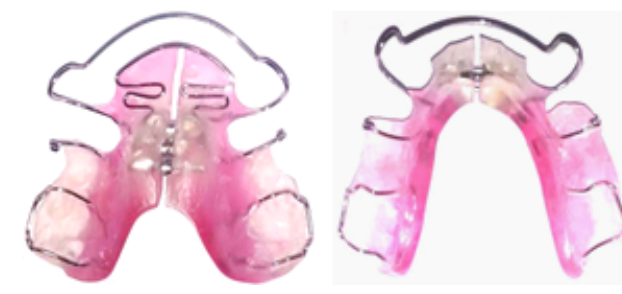

Fig. 1.

Customized

protruding dental

Twin block

appliance used in research

\section{Results and discussions}

We determined the following cranial and dental measurements, and the values of presented case were:

- When the appliance was inserted, it was shown that the mandible was rotated downward by $5^{\circ}$ and forward by
$2.41 \mathrm{~mm}$. The measures of lower facial height were increased by an average of $58 \mathrm{~mm}$ to $65 \mathrm{~mm}$.

- The mandibular position in relation to the cranial base, the angle SNB was increased on average of 10 and the restraining effect of the maxilla from 90 to $84^{\circ}$ for SNA angle.

- The lower incisors were observed to move back in relation to the mandibular plan angle IMPA decreased from $100^{\circ}$ to $89^{\circ}$ and also the inclination of upper incisors to the reference line NB was improved by $7^{\circ}$ from 26 to $19^{\circ}$.

All measurements are summarized in table 1.

Table 1

CEPHALOMETRIC VARIABLES BEFORE AND AFTER FUNCTIONAL TREATMENT

\begin{tabular}{||l|c|c|c|c|c||}
\hline \hline Results & Unit & Minimum & Maximum & Before & After \\
\hline \hline FMA & $\mathrm{mm}$ & 16.00 & 35.00 & 25 & 30 \\
\hline IMPA & $\mathrm{mm}$ & 84.00 & 92.00 & 100 & 89 \\
\hline SNA & $\mathrm{mm}$ & 80.00 & 84.00 & 90.00 & 84.00 \\
\hline SNB & $\mathrm{mm}$ & 78.00 & 82.00 & 78.00 & 79.00 \\
\hline ANB & $\mathrm{mm}$ & 1.00 & 5.00 & 12 & 5.00 \\
\hline SN-OcP & $\mathrm{mm}$ & 14.00 & 14.00 & 14.55 & 14.44 \\
\hline SN-GoGn & $\mathrm{mm}$ & 30.00 & 30.00 & 24.84 & 32.40 \\
\hline Max1-NA & $\mathrm{mm}$ & 22.00 & 22.00 & 26.00 & 19.00 \\
\hline Mand1-NB & $\mathrm{mm}$ & 25.00 & 25.00 & 30.49 & 25.00 \\
\hline Wits & $\mathrm{mm}$ & 0.00 & 4.00 & & \\
\hline
\end{tabular}

Cephalometric variables determined before and after the functional treatment with the polymeric appliances, indicated positive changes in maxillofacial structures (fig. 2).

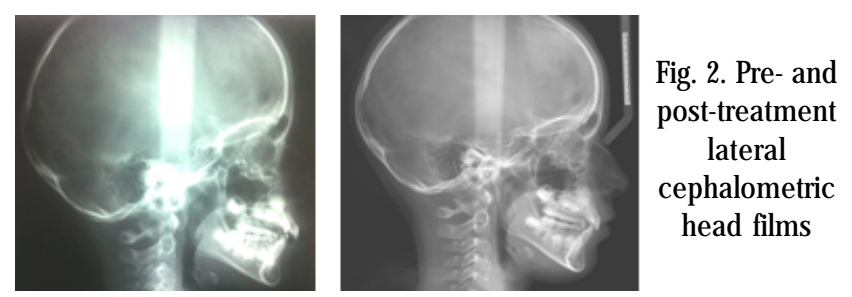

Cardio-respiratory polygraphyc tests, realized before and after the therapy of the presented case, are shown in figure 3.

After wearing the mandibular advancement device for 12 months, AHI increased significantly from 2.6 to 10.2 events per hour of sleep. The initial pretreatment rate of apnea-hyperpnea was 34 events/h of sleep and increased at 81 events/hour in the sleep time, when the polymeric appliances were used. The indices of snoring intensity increased from 4.2 to 51.3 events/hour and also the oxygen desaturation index have significantly variable changes from 3.2 to 10.8 events /hour. Measures of polysomnographic variables for the patient from the initial (t1) and final (t2) indicate significantly differents (table 2).

After the use of polymeric appliances for one year, the patient presented class I Angle dental-skeletal relationship, maxillary expansion, advanced mandible, decreased over jet with the normal lip position, significant growth correction and improved esthetic facial profile (fig. 4 and 5). The subject had normal height and weight for her age and she wasn't obese.

The Twin Block polymeric appliance is used to protrude the mandible, to improving jaw relationships and to correct of Class II, would be expected to expand the pharyngeal airway.

In this study, we have demonstrated AHI and mandibular advancement device have a negative correlation even if the literature showed us otherwise. After all the MAD appliance has been proposed for pharyngeal airway expansion in the treatment of OSA. The mandible rotated 

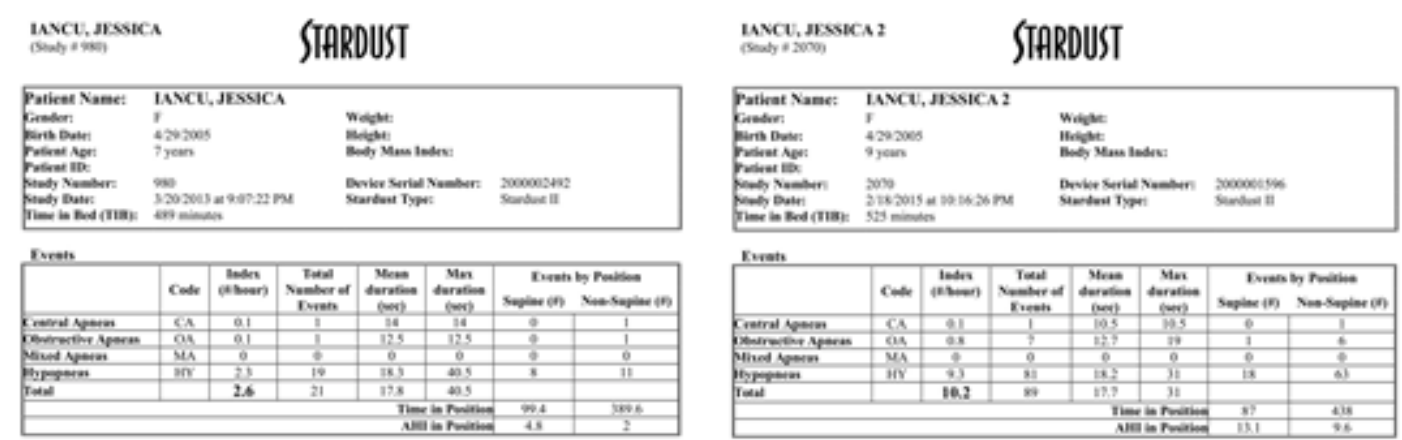

\begin{tabular}{|c|c|c|c|c|}
\hline 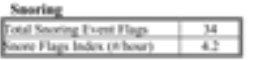 & \multicolumn{2}{|l|}{ an } & \multirow{2}{*}{\multicolumn{2}{|c|}{ 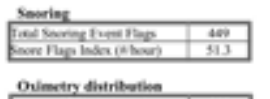 }} \\
\hline Oimetry tituributse & & & & \\
\hline 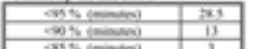 & mes- & & & \\
\hline $\operatorname{ses}(\sin 2)$ & & & 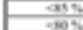 & 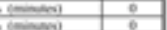 \\
\hline 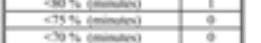 & am & & 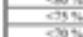 & $=1$ \\
\hline 50 & & & $\frac{-\infty}{602}$ & $=1$ \\
\hline 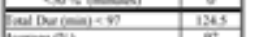 & $x$ & & and bace & 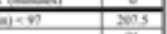 \\
\hline 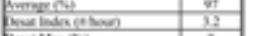 & 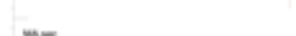 & & 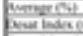 & $+\infty$ \\
\hline nentions & 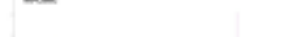 & & 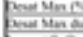 & $\frac{y-1}{4(m)}$ \\
\hline 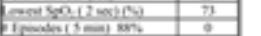 & & & 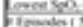 & 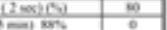 \\
\hline 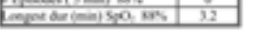 & mom & & inting & \begin{tabular}{|l|l|}
$15 x a m$ & 6 \\
\end{tabular} \\
\hline Hear know & w & & Mart ken & \\
\hline 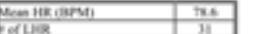 & & & 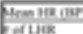 & m \\
\hline 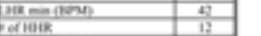 & $\infty$ & & $\lim _{x \rightarrow n} x$ & $\frac{5}{41}$ \\
\hline 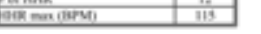 & & & miknilie & 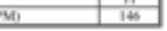 \\
\hline & & Pre & itment & $\begin{array}{c}\text { Posttreatmen } \\
(\mathrm{t} 2)\end{array}$ \\
\hline Age (years) & & 8 & & 9 \\
\hline Weight (kg) & & 25 & & 26 \\
\hline Height $\left(\mathrm{m}^{2}\right)$ & & 1.47 & & 1.48 \\
\hline Body mass index & & 15.3 & & 15.5 \\
\hline Total sleep time (min) & & 489 & & 525 \\
\hline Total number of comp & airway obstruction-events & 34 & & 449 \\
\hline Snoring index (events & & 4.2 & & 51.3 \\
\hline Apnea/hypopnea inde & II (events/hour) & 2.6 & & 10.2 \\
\hline Mean oxygen saturatic & & 97 & & 96 \\
\hline Minimal oxygen satur & $1 \%)$ & 73 & & 80 \\
\hline Oxigen Desaturation I & (events/hour) & 3.2 & & 10.8 \\
\hline
\end{tabular}

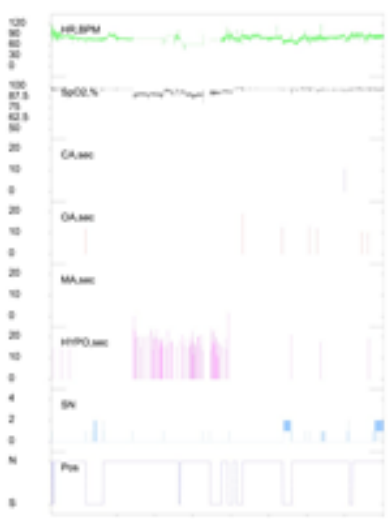

Fig. 3. Respiratory measurements of the presented case

Table 2

MEASURES OF POLYSOMNOGRAPHIC VARIABLES FOR THE PATIENT FROM THE INITIAL (T1) AND FINAL (T2)

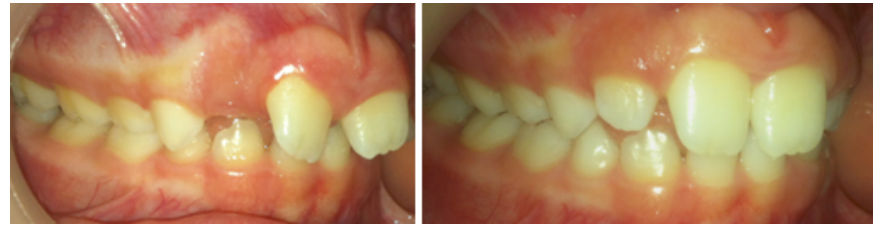

Fig. 4. Pre- and post-treatment intraoral photographs
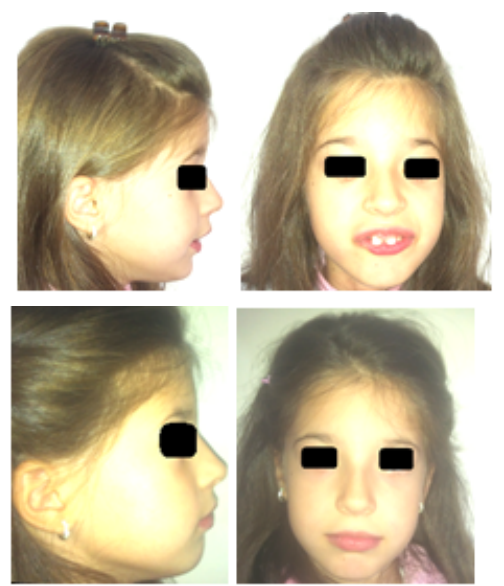

Fig. 5. Pre- and posttreatment facial photographs with the obtained normal lip-seal

posterior (the mandibular plane angle increased $5^{\circ}$ ), which is in accordance with the findings of Bondemark [20]. As a consequence of the posterior rotation of the mandible, the FMA increased. The posterior rotation of the mandible might have been an effect of the anchorage of the MAD at the molar level because if the patient had his mouth open during sleep, there have been an extrusion of the posterior teeth. One year later of orthopedic therapy, sagittal movement was mostly cephalometric changes by the forward growth of the mandible and the restrained effect of the maxilla. The maxillary incisors were observed to move downward in relation to NSL, likely to adapt to the changed position of the mandibular incisors and a decrease in overbite was prevented. The backward movement of the maxillary incisors was possible because the appliance was constructed as there was no acrylic covering of the frontal teeth allowing minor movements. The observed dental and skeletal changes revealed in the present study were also considered to be clinically significant for the diminished overjet and overbite modification, but mainly occurred in the final stage of treatment, visible on facial profile of figure 4 and 5 .

The MAD used have a clinical signiûcant impact on the dental and skeletal system and the usefulness of dental appliances for treating OSA is no longer in question, but in this study has not a favorable effect on mild-to-moderate OSA patient, therefore we need to carefully analyze all aspects of etiological factors in sleep apnea syndrome.

The most significant anatomic risk factor for OSAS in non-obese healthy children is adenotonsillar hypertrophy. The adenoids and tonsils grow progressively during childhood and reach their peak in the prepubertal years, 
coinciding with the peak incidence of childhood OSAS [21]. Disproportionate proliferation of the adenoids and tonsils occurs in children with allergic rhinitis, asthma, and children exposed to cigarette smoking or upper airway respiratory infections, particularly viruses [22-25].

A major symptom of chronic rhino-sinusitis is nasal congestion. Congestion is a cardinal symptom of upper respiratory diseases and is often a focus of treatment in patients with allergic rhinitis. Topical decongestants are the most effective treatment for nasal congestion in subjects with allergic rhinitis, but their adverse effectmakes them suitable for short-term use [26-28].

Surgical treatment for nasal congestion should be reserved for severe or persistent cases of nasal obstruction. The relevant anatomical sites for surgical intervention include the nasal septum, nasal valve, inferior and middle turbinates and nasopharynx. The long-term benefits of septal surgery have been described in a number of studies [29-31]). A trial study in patients diagnosed with a septal deviation requiring surgery to eliminate obstruction reported a statistically significant increase in volume as measured by acoustic rhinometry and a decrease in symptomatic congestion [32]. In addition, a 2- to 3-year follow-up study of patients who underwent septoplasty found significant improvement in nasal breathing and congestion [33]. A retrospective study found a high degree of patient satisfaction in those who had undergone septoplasty for nasal obstruction 3 months earlier [31].

Endoscopic sinus surgery (ESS) has been performed in such cases as a means of relieving congestion. The benefits of ESS in patients with chronic rhinosinusitis have been demonstrated in a number of studies [30-33]. Previous studies have shown the importance of skeletal and pharyngeal (adenoids, tonsils, soft palate) structures, which predispose to possible development of OSA. These signs should be taken care by an orthodontist and otorhinolaryngologist already in the developmental phase of the face, jaw, occlusion and pharyngeal structures during growth [34].

\section{Conclusions}

Early orthodontic treatment with functional appliance appeared to be an accurate device in correcting the molar relationship and reducing overjet in children with retrognathic mandible, but in this study, we can not say that it influenced sleep stages and pharyngeal surgery should be considered after anti-inflammatory therapies and consultation with an otolaryngologist should be mandatory before MAD treatment.

Even if a snoring dental device is a very convenient and comfortable solution we estimate that an interdisciplinary approach is needed to properly diagnose and make a predictable treatment plan for these complex general problems, especially with social context impact.

This study indicates that significant changes in pharyngeal space were made and the mandibular repositioning dental appliance is used with success as a treatment alternative that could benefit patients with mild to moderate obstructive sleep apnea syndrome but only with craniofacial deformities.

The education of the parents and of the small patients to recognize the symptoms of sleep apnea and to apply the available effective treatments with a positive social impact on self-esteem and which recovers the facial aesthetics and functionality is a stringent necessity.

\section{References}

1.*** AMERICAN THORACIC SOCIETY. Standards and indications for cardiopulmonary sleep studies in children. Am. J. Respir. Crit. Care Med. 1996, 153, 866-878

2.CHULZ H. J Clin Sleep Med. 2007; 3(7):752

3.EEG AROUSALS: scoring rules and examples: a preliminary report from the Sleep Disorders Atlas Task Force of the American Sleep Disorders Association. Sleep. 1992;15(2):173-184

4.URSCHITZ MS, GUENTHER A, EITNER S et al. Chest, 2004, 126, 790800

5.ROSEN CL, LARKIN EK, KIRCHNER HL et al. J. Pediatr. 2003, 14, 383-389

6.REDLINE S, TISHLER PV, SCHLUCHTER M, AYLOR J, CLARK K, GRAHAM G. Am. J. Respir. Crit. Care Med. 1999, 159, 1527-1532

7.REDLINE S, TISHLER PV, HANS MG, TOSTESON TD, STROHL KP, SPRY K. Am. J. Respir. Crit. Care Med. 1997, 155, 186-192

8.MITCHELL EA, THOMPSON J M. Acta Pediatr. 2003, 92, 425-429

9.MATTOS J L, WOODARD CR, PAYNE SC.Int forum Allergy Rhinol. 2011, 1, 3-12

10.MELSEN B. Current controversies in orthodontics. Chicago, IL, Quintessences 1991

11.REDLINE S, TISHLER PV, SCHLUCHTER M, AYLOR J, CLARK K, GRAHAM G. Am J Respir Crit Care Med. 1999, 159(5 Pt 1):1527-32

12.LOWE AA, TAKADA K, YAMAGATA BE, SAKUDA M. Am J Orthod. 1985, 88:333-341

13.McNAMARA JA J r. Angle Orthod. 1981; 51:171-202

14.LINDER-ARONSON ADENOIDSS. Acta Otolaryngol Suppl 1970; 265:1132

15.CHARLIER JP, PETROVIC A, STUTZMANN J. Am J Orthod. 1969; 55:71-74

16.SCHUTZTC, DOMINGUEZ GC, HALLINAN MP, CUNHA TC, TUFIK S, Angle Of Orthodontics 2001; 81:222-8

17.BECHIR, E.S., BECHIR, A., ARGHIR, O.C, CIAVOI, G, GIOGA, C, CURT, MOLA, F, DASCALU, IT, Mat. Plast., 54, no.2, 2017, p. 305

18.DIACONU, POPA D., VITALARIU, A., TATARCIUC, M., MUNTEANU, F., Rev. Chim.(Bucharest) , 67, no. 8, 2016, p. 1571

19.BECHIR, A., BECHIR, E.S., MANU, R., BURCEA, A., GIOGA, C., BARBU, H.M., BIRIS, C., CIAVOI, G., DASCALU, I.T, Mat. Plast, 53, no. 4, 2016, p. 661

20.BONDEMARK L. Am J Orthod Dentofacial Orthop 1999; 116:621-8 21.MCCOLLEY SA, CARROLL J L, CURTIS S, LOUGHLIN GM, SAMPSON HA. Chest, 1997, 111, 170-173

22. CHANG SY, GOH DY, WANG XS, TAN TN, ONG NB. Pediatr. Pulmonol. 2004, 38, 210-216

23.LU LR, PEAT JK, SULLIVAN CE. Chest, 2003, 124, 587-593

24.CARVALHO FR, LENTINI-OLIVEIRA DA, PRADO LB, PRADO GF, CARVALHO LB. Cochrane Database Syst Rev, 2007(2): p. CD005520 25.URSCHITZ MS, GUENTHER A, EITNER S et al. Chest, 2004, 126, 790-800

26.THE ALLERGY REPORT. MILWAUKEE, WI: The American Academy of Allergy, Asthma and Immunology; 2000. Managing the patient with allergic rhinitis

27.KEMKER B, LIU X, GUNGOR A, MOINUDDIN R, COREY JP. Otolaryngol Head Neck Surg. 1999; 121(5):567-571

28.KONSTANTINIDIS I, TRIARIDIS S, TRIARIDIS A, KARAGIANNIDIS K, KONTZOGLOU G. Auris Nasus Larynx. 2005; 32(4):369-374

29.STEWART MG, SMITH TL, WEAVER EM, et al. Otolaryngol Head Neck Surg. 2004; 130(3):283-290

30.BHATTACHARYYA N. Arch Otolaryngol Head Neck Surg. 2004; 130(3):329-333

31.NUMMINEN J, DASTIDAR P, RAUTIAINEN M. J Otolaryngol. 2004; 33(2):98-103

32.SMITH TL, MENDOLIA-LOFFREDO S, LOEHRL TA, SPARAPANI R, LAUD PW, NATTINGER AB. Laryngoscope. 2005; 115(12):2199-2205

33. SIPILÄ J, ANTILA J, SUONPÄ Ä, J. Eur Arch Otorhinolaryngol. 1996; 253(4-5):237-239

34.TANGUGSON V, SKATVEDT 0, KRODSTAD 0, LYBERG T. European Respiratory J ournal 1995; 17:57-66

\footnotetext{
Manuscript received: 2.03 .2017
} 